\title{
STUDY OF THE DYNAMICS OF THE TRAVELING BLOCK-CROWN \\ BLOCK MECHANISM OF THE DRILLING RIG WITH TWO ACTIVE DRAWWORKS
}

\author{
Claudia Niculae ${ }^{1}$, Maria Tănase ${ }^{1}$ \\ ${ }^{1}$ Universitatea Petrol-Gaze din Ploieşti, România \\ e-mail: maria.tanase@upg-ploiesti.ro
}

DOI: 10.51865/JPGT.2021.01.07

\begin{abstract}
In the hoisting equipment, the hoisting or lowering of the load at the hook is done with the drilling cable that connects the sheaves from the crown-block and those from the travelling-block. Failure of the drilling line can have catastrophic effects, hence it is very important to evaluate as accurately as possible the values of the lines tensions, so that during the drilling operations they do not exceed their tensile limits.

The present paper deals with the study regarding the dynamics of the of the travelling block- crown block mechanism with two active drawworks and is establishing the expressions for calculation of the tensions from the drilling lines, depending on the load applied at the hook during both hoisting and lowering operations. The calculation is performed for the case of the travelling block-crown block mechanism provided with 3 respectively 4 sheaves and the values of the lines tensions for a hoisting equipment with two active drawworks are compared with the values for the conventional hoisting equipment.
\end{abstract}

Keywords: hoisting, lowering, drilling cable, tension, dual active drawworks

\section{INTRODUCTION}

The dual active drawworks system is relatively new, being used for the first time in 2010 in Mobile Offshore Drilling Unit [3]. Among the advantages of this type of equipment compared to the conventional equipment, we can mention: reduction of the duration for the hoisting operations into / out of the well, redundancy of the system, reduction of the cost for the operations needed to remove the degraded drilling line due to its constructive ability to abandon the classic "cut and slip" operations.

In this paper the distribution of the tensions in the drilling lines is analyzed, through a comparative study between the conventional hoisting equipment and one with two active drawworks. In the case of the latter, the formulas for calculating the tensions of the extreme branches have been established based on kinematic analysis, taking into account the friction between the lines and sheaves and the rotation direction of each sheave [6]. 


\section{CALCULATION}

The determination of the drilling lines tension for the dual drawworks equipment TM1 and TM2 [3, 4, 9] (figure 1) is done for hoisting and lowering the hook load, for the cases analyzed in the kinematic study [6]. This is necessary in order to determine through the limitations imposed on the speeds - the direction of rotation for every sheave in the travelling block - crown block mechanism [8].

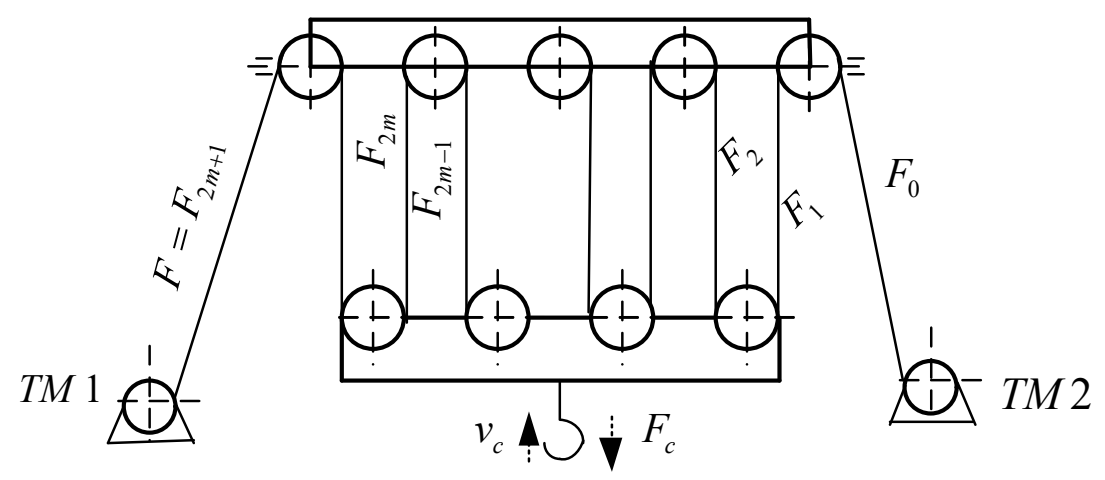

Figure 1. The traveling block-crown block mechanism with two active drawworks [5, 7].

In order to determine the tensions in the different branches of the drilling cable, the following phases must be analyzed:

1. the hoisting;

2. the lowering.

In this paper we analyze the travelling block with 3 sheaves and 4 sheaves.

\section{a. The dual drawworks equipment with 3 sheaves at the traveling block-hoisting}

In figure 2 it is presented the dual drawworks equipment with 3 sheaves at the traveling block and considering the case from the kinematic study [6], with $\frac{v_{A}}{4}<v_{c}<\frac{v_{A}}{2}$, where $v_{A}$ is the speed of the active branche $A$ and $v_{c}$ is the hook speed. The rotation directions are represented for every sheave in the crown block and travelling block.

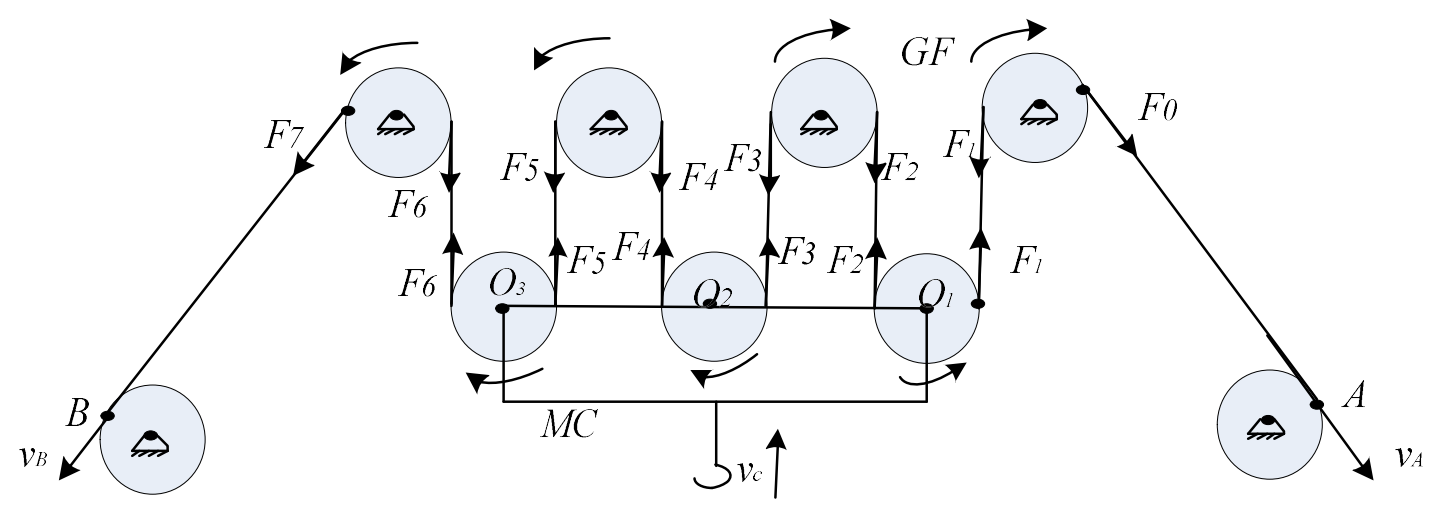

Figure 2. Hoisting -3 sheaves at the traveling block- 
The sheaves efficiencies are:

$\eta=\frac{F_{1}}{F_{0}} \Rightarrow F_{1}=\eta F_{0}$

$\eta=\frac{F_{2}}{F_{1}} \Rightarrow F_{2}=\eta^{2} F_{0}$

$\eta=\frac{F_{3}}{F_{2}} \Rightarrow F_{3}=\eta^{3} F_{0}$

$\eta=\frac{F_{3}}{F_{4}} \Rightarrow F_{4}=\frac{F_{3}}{\eta}=\eta^{2} F_{0}$

$\eta=\frac{F_{4}}{F_{5}} \Rightarrow F_{5}=\frac{F_{4}}{\eta}=\eta F_{0}$

$\eta=\frac{F_{5}}{F_{6}} \Rightarrow F_{6}=\frac{F_{5}}{\eta}=F_{0}$

We make the following notation:

$\beta=\frac{1}{\eta}$

and it results:

$\eta=\frac{F_{6}}{F_{7}} \Rightarrow F_{7}=\frac{F_{6}}{\eta}=\frac{F_{0}}{\eta}=\beta F_{0}$

$F=F_{7}=\beta F_{0}$

The hook load $F_{c}^{\prime}$ is:

$F_{c}^{\prime}=\sum_{i=1}^{6} F_{i}=F_{0}\left(\eta+\eta^{2}+\eta^{3}+\eta^{2}+\eta+1\right)=F_{0}\left(2 \eta+2 \eta^{2}+\eta^{3}+1\right)$

The tension in the line $A$ is:

$$
F_{0}=\frac{F_{c}^{\prime}}{\left(2 \eta+2 \eta^{2}+\eta^{3}+1\right)}=\frac{F_{c}^{\prime}}{\eta\left(2+2 \eta+\eta^{2}+\frac{1}{\eta}\right)}=\frac{\beta F_{c}^{\prime}}{\left(2+\frac{2}{\beta}+\frac{1}{\beta^{2}}+\beta\right)}
$$

The tension in the line $B$ is: 


$$
F=\beta F_{0}=\frac{\beta^{2} F_{c}^{\prime}}{\left(2+\frac{2}{\beta}+\frac{1}{\beta^{2}}+\beta\right)}
$$

In figure 3 it is presented the dual drawworks equipment with 3 sheaves at the traveling block with $\frac{v_{A}}{2}<v_{c}<v_{A}$.

Applying the same algorithm as, the sheaves efficiency is:

$$
\begin{aligned}
& \eta=\frac{F_{1}}{F_{0}} \Rightarrow F_{1}=\eta F_{0} \\
& \eta=\frac{F_{2}}{F_{1}} \Rightarrow F_{2}=\eta^{2} F_{0} \\
& \eta=\frac{F_{2}}{F_{3}} \Rightarrow F_{3}=\frac{F_{2}}{\eta}=\eta F_{0} \\
& \eta=\frac{F_{3}}{F_{4}} \Rightarrow F_{4}=\frac{F_{3}}{\eta}=F_{0} \\
& \eta=\frac{F_{4}}{F_{5}} \Rightarrow F_{5}=\frac{F_{4}}{\eta}=\frac{F_{0}}{\eta} \\
& \eta=\frac{F_{5}}{F_{6}} \Rightarrow F_{6}=\frac{F_{5}}{\eta}=\frac{F_{0}}{\eta^{2}} \\
& \eta=\frac{F_{6}}{F_{7}} \Rightarrow F_{7}=\frac{F_{6}}{\eta}=\frac{F_{0}}{\eta^{3}}=\beta^{3} F_{0} \\
& F=F_{7}=\beta^{3} F_{0}
\end{aligned}
$$

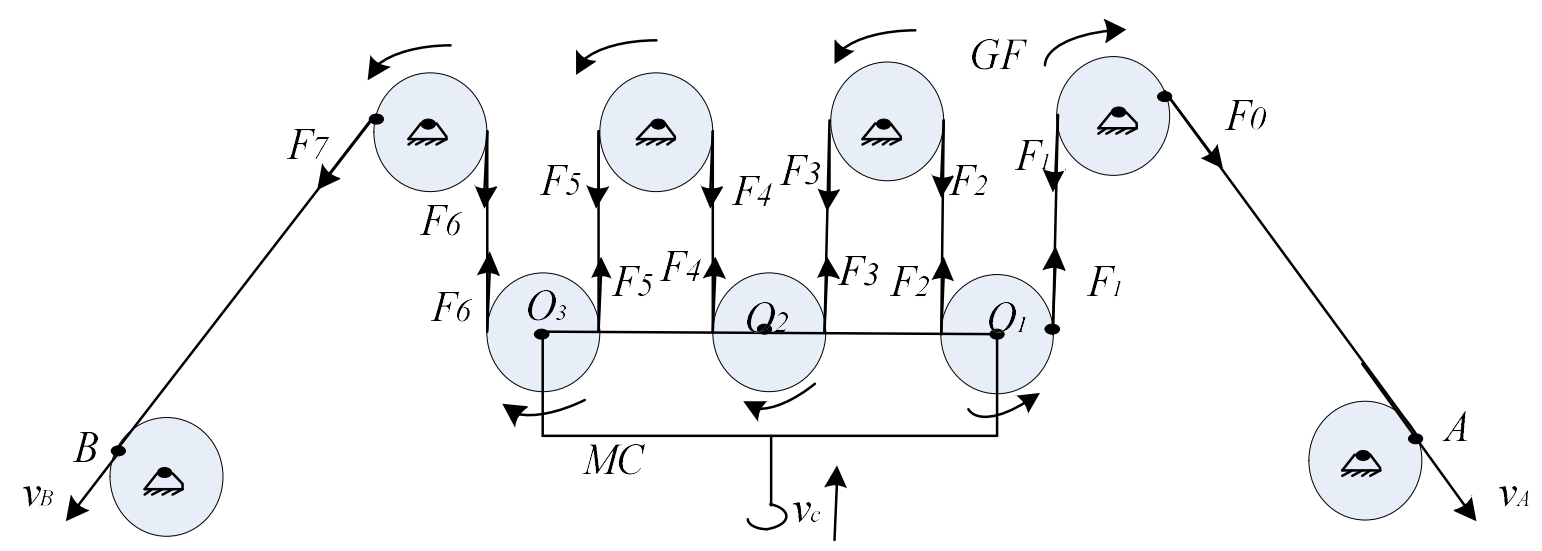

Figure 3. Hoisting -3 sheaves at the traveling block: 
The hook load $F_{c}$ is:

$$
F_{c}^{\prime}=\sum_{i=1}^{6} F_{i}=F_{0}\left(\eta+\eta^{2}+\eta+1+\frac{1}{\eta}+\frac{1}{\eta^{2}}\right)=F_{0}\left(2 \eta+\eta^{2}+1+\frac{1}{\eta}+\frac{1}{\eta^{2}}\right)
$$

The tension in the line $A$ is:

$$
F_{0}=\frac{F_{c}^{\prime}}{\left(2 \eta+\eta^{2}+1+\frac{1}{\eta}+\frac{1}{\eta^{2}}\right)}=\frac{F_{c}^{\prime}}{\eta\left(2+\eta+\frac{1}{\eta}+\frac{1}{\eta^{2}}+\frac{1}{\eta^{3}}\right)}=\frac{\beta F_{c}^{\prime}}{\left(2+\frac{1}{\beta}+\beta+\beta^{2}+\beta^{3}\right)}
$$

The tension in the line $B$ is:

$$
F=\beta^{3} F_{0}=\frac{\beta^{4} F_{c}^{\prime}}{\left(2+\frac{1}{\beta}+\beta+\beta^{2}+\beta^{3}\right)}
$$

\section{b. The dual drawworks equipment with 4 sheaves at the traveling block-hoisting}

Similarly, for 4 sheaves at the travelling block the tensions from the extreme branches were established, using the same speed limitations. The calculation scheme corresponding to the $\frac{v_{A}}{6}<v_{c}<\frac{v_{A}}{4}$ limitations is shown in figure 4 .

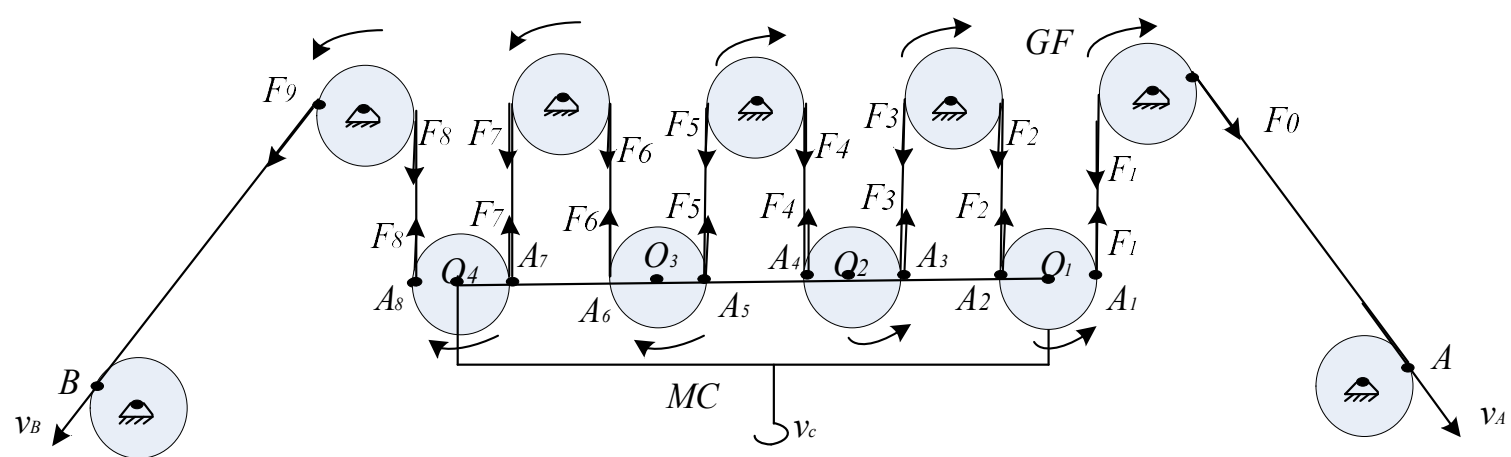

Figure 4. Hoisting - 4 sheaves at the traveling block

The results obtained are presented in table 1.

For lowering a similar analysis of the hoisting is performed and the efficiency of the sheaves is expressed by taking into account that their rotation direction is opposite to the hoisting case. The results obtained are summarized in table 2. 
Table 1. Summary of the study of forces for the dual drawworks equipment with 3, respectively 4 sheaves at the travelling block - hoisting

\begin{tabular}{|c|c|c|}
\hline Case & 3 sheaves & 4 sheaves \\
\hline$\frac{v_{A}}{6}<v_{c}<\frac{v_{A}}{4}$ & - & $\begin{array}{c}F_{0}=\frac{\beta F_{c}^{\prime}}{\left(1+\frac{2}{\beta}+\frac{2}{\beta^{2}}+\frac{2}{\beta^{3}}+\frac{1}{\beta^{4}}\right)} \\
F=\frac{F_{c}^{\prime}}{\left(1+\frac{2}{\beta}+\frac{2}{\beta^{2}}+\frac{2}{\beta^{3}}+\frac{1}{\beta^{4}}\right)}\end{array}$ \\
\hline$\frac{v_{A}}{4}<v_{c}<\frac{v_{A}}{2}$ & $\begin{array}{c}F_{0}=\frac{\beta F_{c}^{\prime}}{\left(2+\frac{2}{\beta}+\frac{1}{\beta^{2}}+\beta\right)} \\
F=\frac{\beta^{2} F_{c}^{\prime}}{\left(2+\frac{2}{\beta}+\frac{1}{\beta^{2}}+\beta\right)}\end{array}$ & $\begin{array}{c}F_{0}=\frac{\beta F_{c}^{\prime}}{\left(2+\frac{2}{\beta}+\frac{1}{\beta^{2}}+\beta+\beta^{2}+\beta^{3}\right)} \\
F=\beta^{3} F_{0}=\frac{\beta^{4} F_{c}^{\prime}}{\left(2+\frac{2}{\beta}+\frac{1}{\beta^{2}}+\beta+\beta^{2}+\beta^{3}\right)}\end{array}$ \\
\hline$\frac{v_{A}}{2}<v_{c}<v_{A}$ & $\begin{array}{l}F_{0}=\frac{\beta F_{c}^{\prime}}{\left(2+\frac{1}{\beta}+\beta+\beta^{2}+\beta^{3}\right)} \\
F=\frac{\beta^{4} F_{c}^{\prime}}{\left(2+\frac{1}{\beta}+\beta+\beta^{2}+\beta^{3}\right)}\end{array}$ & $\begin{array}{l}F_{0}=\frac{\beta F_{c}^{\prime}}{\left(2+\frac{1}{\beta}+\beta+\beta^{2}+\beta^{3}+\beta^{4}+\beta^{5}\right)} \\
F=\frac{\beta^{6} F_{c}^{\prime}}{\left(2+\frac{1}{\beta}+\beta+\beta^{2}+\beta^{3}+\beta^{4}+\beta^{5}\right)}\end{array}$ \\
\hline $\begin{array}{l}\text { Conventional } \\
\text { hoisting } \\
\text { equipment }\end{array}$ & $\begin{aligned} F_{0} & =\frac{\beta-1}{\beta\left(\beta^{6}-1\right)} F_{c}^{\prime} \\
F & =\beta^{6} \frac{\beta-1}{\beta^{6}-1} F_{c}^{\prime}\end{aligned}$ & $\begin{array}{c}F_{0}=\frac{\beta-1}{\beta\left(\beta^{8}-1\right)} F_{c}^{\prime} \\
F=\beta^{8} \frac{\beta-1}{\beta^{8}-1} F_{c}^{\prime}\end{array}$ \\
\hline
\end{tabular}


Table 2. Forces for the dual drawworks equipment with 3, respectively 4 sheaves at the travelling block - lowering

\begin{tabular}{|c|c|c|}
\hline Case & 3 sheaves & 4 sheaves \\
\hline$\frac{v_{A}}{6}<v_{c}<\frac{v_{A}}{4}$ & - & $\begin{array}{l}F_{0}=\frac{F_{c}^{\prime}}{\beta\left(1+2 \beta+2 \beta^{2}+2 \beta^{3}+2 \beta^{4}\right)} \\
F=\frac{F_{c}^{\prime}}{\left(1+2 \beta+2 \beta^{2}+2 \beta^{3}+2 \beta^{4}\right)}\end{array}$ \\
\hline$\frac{v_{A}}{4}<v_{c}<\frac{v_{A}}{2}$ & $\begin{array}{l}F_{0}=\frac{F_{c}^{\prime}}{\beta\left(2+2 \beta+\beta^{2}+\frac{1}{\beta}\right)} \\
F=\frac{F_{c}^{\prime}}{\beta^{2}\left(2+2 \beta+\beta^{2}+\frac{1}{\beta}\right)}\end{array}$ & $\begin{array}{c}F_{0}=\frac{F_{c}^{\prime}}{\beta\left(2+2 \beta+\beta^{2}+\frac{1}{\beta}+\frac{1}{\beta^{2}}+\frac{1}{\beta^{3}}\right)} \\
F=\frac{F_{c}^{\prime}}{\beta^{4}\left(2+2 \beta+\beta^{2}+\frac{1}{\beta}+\frac{1}{\beta^{2}}+\frac{1}{\beta^{3}}\right)}\end{array}$ \\
\hline$\frac{v_{A}}{2}<v_{c}<v_{A}$ & $\begin{array}{l}F_{0}=\frac{F_{c}^{\prime}}{\beta\left(2+\beta+\frac{1}{\beta}+\frac{1}{\beta^{2}}+\frac{1}{\beta^{3}}\right)} \\
F=\frac{F_{c}^{\prime}}{\beta^{4}\left(2+\beta+\frac{1}{\beta}+\frac{1}{\beta^{2}}+\frac{1}{\beta^{3}}\right)}\end{array}$ & $\begin{array}{l}F_{0}=\frac{F_{c}^{\prime}}{\beta\left(2+\beta+\frac{1}{\beta}+\frac{1}{\beta^{2}}+\frac{1}{\beta^{3}}+\frac{1}{\beta^{4}}+\frac{1}{\beta^{5}}\right)} \\
F=\frac{F_{c}^{\prime}}{\beta^{6}\left(2+\beta+\frac{1}{\beta}+\frac{1}{\beta^{2}}+\frac{1}{\beta^{3}}+\frac{1}{\beta^{4}}+\frac{1}{\beta^{5}}\right)}\end{array}$ \\
\hline $\begin{array}{l}\text { Conventional } \\
\text { hoisting } \\
\text { equipment }\end{array}$ & $\begin{aligned} F_{0} & =\beta^{6} \frac{\beta-1}{\left(\beta^{6}-1\right)} F_{c}^{\prime \prime} \\
F & =\frac{\beta-1}{\beta\left(\beta^{6}-1\right)} F_{c}^{\prime \prime}\end{aligned}$ & $\begin{aligned} F_{0} & =\beta^{8} \frac{\beta-1}{\left(\beta^{8}-1\right)} F_{c}^{\prime \prime} \\
F & =\frac{\beta-1}{\beta\left(\beta^{8}-1\right)} F_{c}^{\prime \prime}\end{aligned}$ \\
\hline
\end{tabular}

We consider that the force at the drilling hook is constant, the values of the tensions that develop in the extreme branches of the drilling cable is established (for coefficient $\beta=1,04$ ) 1.04 (table 1 and table 2). This analysis is done for both, the conventional and the dual drawworks cases. In the dual drawworks case, a more uniform distribution of the load of the cable branches is observe (table 3 and 4) since the value of the maximum tension decreases and the value of the minimum tension are increase, so that the differences between them are smaller. 
Table 3. The analysis of the loads distribution in the cable extreme branches - hoisting

\begin{tabular}{|c|c|c|}
\hline Case & 3 sheaves & 4 sheaves \\
\hline Conventional hoisting equipment & $F_{0}=0.1449 F_{c}^{\prime}$ & $F_{0}=0.1043 F_{c}^{\prime}$ \\
& $F_{0}=0.1907 F_{c}^{\prime}$ & $F_{0}=0.1485 F_{c}^{\prime}$ \\
\hline $\begin{array}{c}\text { Difference between the extremes } \\
\text { values }\end{array}$ & $0.0458 F_{c}^{\prime}$ & $0.0442 F_{c}^{\prime}$ \\
\hline$\frac{v_{A}}{4}<v_{c}<\frac{v_{A}}{2}$ & $F_{0}=0.1766 F_{c}^{\prime}$ & $F_{0}=0.1284 F_{c}^{\prime}$ \\
& $F_{0}=0.1837 F_{c}^{\prime}$ & $F_{0}=0.1440 F_{c}^{\prime}$ \\
\hline $\begin{array}{c}\text { Difference between the } \\
\text { extremes values }\end{array}$ & $\mathbf{0 . 0 0 7 1} F_{c}^{\prime}$ & $\mathbf{0 . 0 1 5 6} F_{c}^{\prime}$ \\
\hline$\frac{v_{A}}{2}<v_{c}<v_{A} \cdot$ & $F_{0}=0.1675 F_{c}^{\prime}$ & $F_{0}=0.1210 F_{c}^{\prime}$ \\
& $F_{0}=0.1884 F_{c}^{\prime}$ & $F_{0}=0.1472 F_{c}^{\prime}$ \\
\hline $\begin{array}{c}\text { Difference between the extremes } \\
\text { values }\end{array}$ & $0.0209 F_{c}^{\prime}$ & $0.0262 F_{c}^{\prime}$ \\
\hline
\end{tabular}

Table 4. The analysis of the loads distribution in the cable extreme branches - lowering

\begin{tabular}{|c|c|c|}
\hline Case & 3 sheaves & 4 sheaves \\
\hline Conventional hoisting equipment & $F_{0}=0.1907 F_{c}^{\prime}$ & $F_{0}=0.1485 F_{c}^{\prime}$ \\
& $F_{0}=0.1449 F_{c}^{\prime}$ & $F_{0}=0.1043 F_{c}^{\prime}$ \\
\hline $\begin{array}{c}\text { Difference between the extremes } \\
\text { values }\end{array}$ & $0.0458 F_{c}^{\prime}$ & $0.0442 F_{c}^{\prime}$ \\
\hline$\frac{v_{A}}{4}<v_{c}<\frac{v_{A}}{2}$ & $F_{0}=0.1570 F_{c}^{\prime}$ & $F_{0}=0.1211 F_{c}^{\prime}$ \\
& $F_{0}=0.1509 F_{c}^{\prime}$ & $F_{0}=0.1077 F_{c}^{\prime}$ \\
\hline $\begin{array}{c}\text { Difference between the extremes } \\
\text { values }\end{array}$ & $\mathbf{0 . 0 0 6 1} F_{c}^{\prime}$ & $\mathbf{0 . 0 1 3 4} F_{c}^{\prime}$ \\
\hline$\frac{v_{A}}{2}<v_{c}<v_{A} \cdot$ & $F_{0}=0.1650 F_{c}^{\prime}$ & $F_{0}=0.1280 F_{c}^{\prime}$ \\
\hline $\begin{array}{c}\text { Difference between the extremes } \\
\text { values }\end{array}$ & $F_{0}=0.1469 F_{c}^{\prime}$ & $F_{0}=0.1050 F_{c}^{\prime}$ \\
\hline
\end{tabular}

\section{CONCLUSIONS}

Analysis of the traveling block-crown block it was found that for the dual drawworks equipment, a more uniform distribution of the tensions in the extreme branches of the drilling cable is obtained, both for hoisting and lowering. The smallest difference between the extreme values of the tensions appears if the speed at the drilling hook is lower (case $\frac{v_{A}}{4}<v_{c}<\frac{v_{A}}{2}$ in tables 3 and 4 ). 


\section{REFERENCES}

[1] Cristea, V., Grădişteanu, I., Peligrad, N., Instalaţii şi utilaje pentru forarea sondelor, Editura Tehnică, Bucureşti, 1985.

[2] Drillmec Drilling Technologies, Training MR8000 Semitrailer, 2010.

[3] Fivelstad O. et all., Dual Active Heave Drilling Drawworks: From Concept to Operaţional Life, IADC/SPE 168019 Texas, 2014.

[4] Kyllingstad A., Dual Drawworks Provide Operaţional Redundancy and Reduce Cut and Slip Costs, SPE/IADC 79826 Amsterdam, 2003.

[5] Niculae, G.C., Utilaj petrolier. Indrumar de laborator si activitati aplicative. Editura UPG din Ploiesti, 2016.

[6] Niculae, G.C., Tănase, M. Study of the Kinematics of the Traveling Block-Crown Mechanism of the Drilling Rig Equipped with Two Drawworks. Petroleum - Gas University of Ploiesti Bulletin, Technical Series, Vol. 70 Issue 3, pp. 45-53, 2018

[7] Popovici, Al. et all., Calculul şi construcţia utilajului pentru forajul sondelor de petrol. Editura Universităţi din Ploieşti, 2005.

[8] Pupăzescu Al., Mecanică teoretică şi rezistenţa materialelor, Vol. I., Editura Universităţii din Ploieşti, 2004.

[9] Kyllingstad A., Dual Drawworks Provide Operaţional Redundancy and Reduce Cut and Slip Costs, 79826 SPE/IADC, Drilling Conference, Amsterdam, Netherlands, February 2003. 